\title{
O DISCURSO POLÍTICO DA EXTREMA-DIREITA BRASILEIRA NA ATUALIDADE
}

\author{
(The political discourse of the Brazilian far-right nowadays) \\ (El discurso político de la extrema derecha brasileña en la actualidad)
}

\author{
Argus Romero Abreu de Morais ${ }^{1}$ \\ Universidade Federal de São João del Rei
}

\section{RESUMO}

No presente estudo, propomo-nos a investigar a organização interdiscursiva, argumentativa e metafórica do discurso político da extrema-direita brasileira na atualidade. Para tanto, analisaremos o voto do então deputado federal Jair Bolsonaro (PSL) na Câmara dos Deputados, no dia 17 de abril de 2016, e três enunciados publicados em seu perfil na rede social Facebook. Nesse intuito, na primeira seção, definiremos o que entendemos por discurso político da extrema-direita brasileira; na segunda, caracterizaremos tal discurso na interface entre interação discordante e discurso intolerante; na terceira, discorreremos sobre a categoria de metáforas emergentes distribuídas; por fim, na quarta, analisaremos o corpus selecionado.

Palavras-chave: Discurso político. Extrema-direita brasileira. Argumentação. Interação discordante. Discurso intolerante. Metáforas emergentes distribuídas.

\begin{abstract}
In this study, we aim to investigate the interdiscursive, argumentative and metaphorical organization of the brazilian far-right discourse nowadays. Our corpus is composed by the congressman Jair Bolsonaro's vote in the Chamber of Deputies, on April 17, 2016, and three statements published in his profile on the Facebook. In the first section, we will define what we mean by political discourse of the brazilian far-right; in the second one, we will characterize such discourse as discordant interaction and intolerant discourse; in the third one, we will explore the category of distributed emergent metaphors; in the fourth one, we will evaluate our corpus.
\end{abstract}

Keywords: Political discourse. Brazilian far-right. Argumentation. Discordant interaction. Intolerant discourse. Distributed emergent metaphors.

\section{RESUMEN}

En el presente estudio, nos proponemos investigar la organización interdiscursiva, argumentativa y metafórica del discurso político de la extrema derecha brasileña en la actualidad. En ese sentido, analizaremos el voto del entonces diputado federal Jair Bolsonaro (PSL) en la Cámara de Diputados, el 17 de abril de 2016, y tres enunciados publicados en su perfil en la red social Facebook. En ese sentido, en la primera sección, definiremos lo que entendemos por discurso político de la extrema derecha brasileña; en la segunda, caracterizaremos tal discurso en la interfaz entre interacción discordante y discurso intolerante; en la tercera, discurriremos sobre la categoría de metáforas emergentes distribuidas; por último, en la cuarta, analizaremos el corpus seleccionado.

Palabras-clave: Discurso político. Extrema-derecha brasileña. Argumentación. Interacción discordante. Discurso intolerante. Metáforas emergentes distribuidas.

\footnotetext{
${ }^{1}$ Professor colaborador e pós-doutorando (PNPD/CAPES) no Programa de Pós-Graduação em Letras: Teoria Literária e Crítica da Cultura da Universidade Federal de São João del-Rei (PROMEL/UFSJ), Campus Dom Bosco. Email: argusromero@yahoo.com.br
} 
Recebido em: agosto 2018

Aceito em: março 2019

DOI: $10.26512 /$ les.v20i1.12129

\section{INTRODUÇÃO}

No presente estudo, almejamos compreender a atual movimentação simbólica dos grupos sociais considerados mais extremistas na direita política brasileira, os quais têm conseguido se afirmar com bastante representatividade no debate público no país. Para tanto, investigaremos a organização interdiscursiva, argumentativa e metafórica dos posicionamentos de um dos principais representantes da extrema-direita brasileira, o antigo deputado federal e atual presidente da república Jair Messias Bolsonaro (Partido Social Liberal - PSL). Como corpus, selecionamos seu voto proferido na Câmara dos Deputados na época em que era parlamentar, no dia 17 de abril de 2016, na sessão que aprovou a abertura do processo de impeachment da então presidente da república, Dilma Rousseff (Partido dos Trabalhadores - PT), e três enunciados publicados em seu perfil oficial na rede social Facebook.

Dito isso, seguiremos o seguinte percurso: na primeira seção, definiremos o que entendemos por extrema-direita política brasileira na atualidade; na segunda, caracterizaremos seu discurso como uma interface entre interação discordante, nos termos de Emediato (2011), e discurso intolerante, conforme proposta de Barros (2007); na terceira, discorreremos sobre a categoria de metáforas emergentes distribuídas, seguindo os pressupostos de Morais (2016); por fim, na quarta, analisaremos o corpus selecionado.

\section{JUNHO DE 2013 E A EXTREMA-DIREITA BRASILEIRA}

Segundo Charaudeau (2008), o discurso político engloba tudo aquilo que diz respeito à organização da vida em sociedade e ao governo da coisa pública. Nesse sentido, o fim último desse discurso é o "bem soberano", o qual se ancora em uma espécie de pacto de reconhecimento de um dado "ideal social", constituído na contradição entre a busca de valores universais e o respeito à pluralidade de interesses entre os distintos grupos em uma dada sociedade. Considerando essa perspectiva, quais seriam as características de um discurso político pautado em propostas que não almejam construir o consenso?

Para Arantes (2014, p. 1), as manifestações de junho de 2013 foram responsáveis pela eclosão do que chama de "Nova Direita" no Brasil, isto é, "uma direita não convencional, que não está contemplada pelos esquemas tradicionais da política”, almejando evitar qualquer mudança no status quo da sociedade brasileira. Ribeiro (2015), por sua vez, assevera que, enquanto o diálogo é possível entre grupos moderados de direita e de esquerda, o extremismo político inviabiliza qualquer 
tentativa de construção de uma pauta comum. De acordo com sua perspectiva, "o que distingue a extrema-direita hoje no Brasil é quase que mais uma agenda de costumes do que uma agenda política. [...] A extrema-direita está se distinguindo do restante por um ódio cabal aos direitos humanos" (RIBEIRO, 2015, p. 1).

Löwy (2015, p. 663) ressalta que, no Brasil, diferentemente da Europa, não existem partidos políticos constituídos exclusivamente em torno de pautas raciais, de modo que "o elemento mais preocupante da extrema-direita conservadora no Brasil, que não tem um equivalente direto na Europa, é o apelo aos militares". Apesar disso, atualmente, haveria duas semelhanças entre ambas as realidades, quais sejam: (i) a ideologia repressiva, expressa pelo culto à violência policial, a qual, no Brasil, é representada institucionalmente pela denominada "Bancada da Bala"2; (ii) a intolerância com as minorias sexuais, com forte referência católica na França e evangélica, no Brasil ${ }^{3}$.

Para Chauí (2016), a expansão dos grupos radicais de direita no país está vinculada a um movimento pouco percebido dentro do fenômeno mais complexo das manifestações de junho de 2013, demonstrado tanto pela aceitação crescente de pautas ultraconservadoras pela opinião pública quanto pelo aumento da sua representatividade institucional na política brasileira. A partir de 2015, afirma a pensadora, pôde-se perceber com mais clareza o crescimento da demanda pelo retorno da ditadura militar no Brasil, uma maior presença dos grupos de extrema-direita Tradição, Família e Propriedade (TFP) e, nas instâncias representativas, o fortalecimento da bancada parlamentar dos 3Bs (Boi, Bala, Bíblia), vinculadas, respectivamente, às demandas dos setores agropecuaristas, das instituições militares e de segurança pública e dos cristãos conservadores. A respeito da relação entre o projeto neoliberal e a religiosidade no país, Chauí (2016, p. 2, grifos nossos) acrescenta:

Uma das características do neoliberalismo é a maneira como ele concebe o indivíduo, que não é entendido nem como parte de uma classe social, nem como ser em formação que vai se relacionar com o restante da sociedade. O indivíduo não é pensado nem como átomo nem como classe, mas como um investimento. [...] As igrejas evangélicas [neopentecostais] se apropriam desse ideário e o desenvolvem por meio de uma teologia - a teologia da prosperidade, que considera cada indivíduo justamente como um investimento ou uma empresa. [...] Há, portanto, um fenômeno de fortalecimento da ideologia neoliberal e das concepções conservadoras

\footnotetext{
${ }^{2}$ Consoante Faganello (2015, p. 150. Grifos nossos), “[a] Bancada da Bala é a representante política de um conjunto de ideias e atitudes, que se fundamentam na percepção de que o contexto social está marcado por uma crescente e constante insegurança e desordem pública radical”. Nesse sentido, "[c]oncebe-se uma apreciação da autoridade policial como uma força portadora de uma autonomia radical, a exaltação das virtudes guerreiras e do heroísmo da figura policial se conjugam com um discurso [securitário-autoritário] que entende a violência como ferramenta purificadora, legitimadora e resolutiva dos problemas sociais" (FAGANELLO, 2015, p. 151. Grifos nossos).

${ }^{3}$ Para Villazón (2015, p. 164), “a América Latina tem uma longa tradição de presença evangélica, mas nas últimas décadas houve um salto significativo, especialmente em sua versão pentecostal. Esse crescimento fortaleceu a sua capacidade de influência na agenda pública através de partidos evangélicos ou, mais frequentemente, por meio de associações 'pró-vida' e 'pró-família'. Enquanto no início do século XX a agenda evangélica lutava pela separação entre Igreja e Estado, hoje suas posturas contra o avanço da 'agenda gay' e da 'ideologia de gênero' aproximam esses grupos aos conservadores católicos na luta contra as mudanças liberalizantes na família e na sociedade”.
} 
da classe média por meio da maneira como as igrejas evangélicas incorporam o neoliberalismo, com uma teologia para isso. Se você juntar o conservadorismo com o reacionarismo da classe média urbana e a presença avassaladora das igrejas evangélicas, além de toda a discussão sobre a vida no campo (a reforma agrária), vai entender por que politicamente se exprime, de modo efetivo, nos grupos do "boi, bala e Bíblia", a pauta ultraconservadora que está aí.

Destarte, segundo a autora, a convergência entre as pautas da "Bancada BBB"4 decorre, dentre outros fatores, da reformulação evangélica da concepção neoliberal de indivíduo dentro das estruturas sociais excludentes da sociedade brasileira, perpassando os âmbitos político, social, econômico e religioso. Consoante a filósofa, tais estruturas se perpetuam através do exercício da violência estruturante, a qual, historicamente, tem funcionado como o principal meio, sobretudo do Estado, de manutenção da ordem pública. Essa relação entre violência estruturante e ordem pública funda-se nos ideais de hierarquia, de verticalidade, de conservadorismo e de autoritarismo, bem como pela afirmação dos privilégios como direitos das classes mais abastadas e dos direitos dos grupos marginalizados como assistencialismos. Com isso, a violência, paradoxalmente, legitima-se como expressão da ordem.

Com base na pesquisa do Comitê Gestor da Internet no Brasil, em 2012 - na qual se demonstrou que $74 \%$ dos brasileiros conectados utilizavam redes sociais, sendo o Facebook a preferida desses internautas -, Silveira (2015) assevera que não é mais possível analisar a construção de uma esfera de debate público no Brasil sem considerar o papel dos ambientes virtuais. No seu dizer, “[s]e compararmos com as igrejas, escolas, sindicatos, associações e núcleos de partidos, o Facebook se destaca como um terreno comunicativo com o maior número de debates e embates políticos que incorporam mais pessoas" (SILVEIRA, 2015, p. 224).

O pesquisador pondera ainda que, desde as manifestações de junho de 2013, a Nova Direita tem conseguido se aproveitar melhor dos espaços virtuais, organizando manifestações contra o

\footnotetext{
${ }^{4} \mathrm{O}$ discurso de extrema-direita é constituído pela confluência de distintos fatores e ser apenas neoliberal, cristão conservador ou a favor de medidas de segurança não colocaria, necessariamente, nenhum indivíduo ou grupo nesse espectro político. É preciso haver, fundamentalmente, a intolerância ao outro. Ademais, a complexa composição social dos grupos extremistas de direita no Brasil aponta para uma diversidade de matizes ideológicos, embora pareça convergir para uma espécie de sobredeterminação discursiva - trataremos melhor desse conceito na terceira seção deste texto. Por exemplo, na atualidade, há grupos religiosos com tendências fundamentalistas favoráveis ao avanço do neoliberalismo e intolerantes a qualquer movimento de reforma da política antidrogas, de descriminalização do aborto e de legalização das relações homoafetivas, não estando obrigatoriamente sintonizados com pautas como a intervenção militar e a liberação do porte de armas. Visto que parte significativa dos grupos evangélicos neopentecostais mora nas periferias das grandes cidades, os mesmos tornam-se vítimas potenciais de todos os tipos de violência urbana, incluindo a do arbítrio policial. Em sentido contrário, como principais vítimas da violência patrimonial e maiores usufruidores da estrutura burocrática do Estado, seja pela empregabilidade, seja pelo uso de parte significativa dos seus serviços, há setores expressivos da classe média não alinhados ao neoliberalismo e à Teologia da Prosperidade, embora afinados com o discurso securitário-autoritário - nos termos de Faganello (2015) e com a proposta de governos militares. Para uma análise comparativa entre os eleitores das Bancadas da Bala e da Bíblia, consultar Faganello (2015).
} 
governo de Dilma Rousseff e contrárias a pautas ditas de esquerda, bem como canalizando, de forma eficiente e significativa, as perspectivas de grupos conservadores de distintos matizes e tradições para concordâncias a respeito de temas como orientação sexual, políticas de gênero e criminal, educação, concepção de família e outros debates centrados na discussão dos valores morais ${ }^{5}$.

Assim, de forma geral, podemos perceber a (re)organização simbólica do discurso da extrema-direita brasileira atual com base na convergência entre distintas culturas conservadoras, tais como: (i) a compreensão do indivíduo como investimento e como empresa, (ii) a propriedade privada como direito sagrado, (iii) o acúmulo de riqueza como principal índice de liberdade e de progresso individual, social e espiritual, (iv) a família cristã como fiadora dos valores morais, (v) a rigidez corporativa/hierárquica como princípio da organização social, (vi) a (re)aproximação entre Estado e Religião como garantia de hegemonia política dos grupos dominantes e (vii) o uso da violência como condição estruturante da ordem e do progresso.

\section{ENTRE A DISCORDÂNCIA E A INTOLERÂNCIA: A NEGAÇÃo DA ALTERIDADE COMO PRINCÍPIO}

A partir da análise dos gêneros discursivos "entrevista" e "debate político na televisão", Emediato (2011) avalia as características dos discursos construídos em situações enunciativas regulares nas quais a divergência de opiniões entre os participantes se mantém sem que, com isso, haja a ruptura do contrato comunicacional. Nessas situações enunciativas, em momento algum há concordâncias, acordos e negociações entre os interlocutores, sendo elas, por consequência, definidas como "interações discordantes".

Segundo Emediato (2011), as interações discordantes se associam, parcialmente, às refutações dialéticas aristotélicas, subdivididas em refutações heurísticas e erísticas. No caso das primeiras, elas manifestam o esforço dos interlocutores em produzirem conclusões mais adequadas à realidade, tendo por pressuposto realizar objetivos comuns e transcender a centralidade no ego focada em vencer o debate - em benefício da alteridade, isto é, da legitimação da proposta do outro. Como exemplo, aponta o "debate acadêmico". As refutações erísticas, por seu turno, são marcadas pelo antagonismo extremado entre os atores em uma dada situação comunicativa, de modo que os interesses individuais sobrepujam os objetivos comuns, como no caso do "debate político eleitoral". No entanto, apesar da não validação axiológica entre os discursos antagonistas, os participantes

\footnotetext{
${ }^{5}$ No discurso da extrema-direita brasileira, a própria concepção de trabalho é avaliada sob uma perspectiva moral, definindo os grupos entre produtivos/eficientes e improdutivos/ineficientes, sendo reforçada por uma ética neoliberal pautada na competição e no individualismo. Nessa perspectiva, é frequente o uso da metáfora "parasita" para grupos marginalizados, como pobres, beneficiários de programas sociais, mulheres, negros, nordestinos e refugiados. Sobre a produção neoliberal das subjetividades, consultar Dardot e Laval (2016).
} 
sustentam o contrato comunicacional existente, respeitando o script de interação e demonstrando esforço cognitivo e afetivo, direcionado, em geral, a um terceiro (tiers), o qual funcionaria como o verdadeiro destinatário da argumentação.

Em um nível mais avançado de negação da alteridade, Barros (2007) analisa o discurso separatista no Brasil através do que chama de "discursos intolerantes", os quais são caracterizados do seguinte modo: primeiro, pela organização narrativa como discurso de sanção; segundo, pelo caráter passional, com foco nas paixões do medo e do ódio; terceiro, pelos percursos temáticos da diferença. Tais discursos se constituem no/pelo cruzamento de distintas formas de intolerância, como a étnicoracial, a linguística, a religiosa, a política e a socioeconômica, organizando-se, contudo, através de uma espécie de forma de intolerância de base. Para Barros (2007, p. 150):

O discurso intolerante é, sobretudo, um discurso de sanção aos sujeitos considerados maus cumpridores de certos contratos sociais (por exemplo, de branqueamento da sociedade, de pureza linguística) e que, portanto, devem ser reconhecidos como pretos ignorantes, usuários de língua incorreta, índios, bárbaros, judeus exploradores, árabes fanáticos, e punidos (com a perda de direitos, de emprego, com a morte).

Logo, a sanção se manifestaria de maneira passional, mobilizando as emoções dos seus interlocutores em prol da afirmação do seu grupo e da negação do outro, aquele que simbolizaria a ameaça, a corrupção dos valores, a degeneração, o parasitismo etc. Para tanto, as narrativas se desenvolvem através de percursos temáticos da diferença, os quais constroem de forma estanque as características de si e do outro com foco naquilo que os separam, isto é, que os opõem.

A nosso ver, o posicionamento discursivo do então deputado federal Jair Bolsonaro, como representante do Congresso Nacional brasileiro, emerge na confluência instável entre a refutação erística - interação discordante - e a intolerância, as quais se diferenciam pelo teor de negação da alteridade, embora compartilhem essa mesma negação. Como político, deve cumprir um dado script em relação aos seus pares congressistas e à sociedade, preservando o decoro parlamentar exigido pela sua posição institucional, seja em relação aos seus apoiadores, seja em relação aos seus opositores; todavia, ao defender pautas que negam o respeito à alteridade e à dignidade humana, transforma a discordância em intolerância, extrapolando o limite do que se é permitido dizer, social e juridicamente.

\section{A METÁFORA COMO FENÔMENO COGNITIVO-DISCURSIVO CONSTITUTIVO DA LINGUAGEM}

Conforme Lakoff e Johnson (1985), a metáfora é o próprio fundamento que organiza a língua em uso. Para os estudiosos, as experiências corpóreas dos indivíduos possibilitam a elaboração de 
parâmetros linguístico-cognitivos organizadores da linguagem humana, a saber, metáforas estruturais: quando um termo $\mathrm{X}$ adquire o sentido de um termo $\mathrm{Y}$; metáforas de orientação: quando estabelecem um parâmetro espacial para dar valores a determinados conceitos, associando o "mais", o "maior" e o "no alto" a valores positivos e atribuindo ao "menos", ao "menor" e ao "embaixo" sentidos negativos; metáforas ontológicas: quando permitem nominalizar as entidades, as emoções e as substâncias, referenciando-as, agrupando-as e quantificando-as.

Consoante Cameron e Deignam (2009), a "metáfora conceitual” em Lakoff e Johnson (1985) ainda parece estar vinculada a certo cognitivismo a-histórico, priorizando a universalidade dos conceitos em detrimento da variação cultural e da sua construção situacional interativa. É através do que chamam de "uso e reuso dialógico" entre os sujeitos que se torna possível convencionar os diferentes aspectos envolvidos na conformação dinâmica online de novas metáforas, as quais associam conteúdos ideacionais (a expressão na/pela linguagem de conteúdos oriundos das experiências concretas dos falantes), valores, afetos, formas gramaticais e pragmáticas. Nesse viés, a metáfora seria um fenômeno da linguagem que emerge como produção processual intersubjetiva e que evolui por meio da contínua adaptação local dos (re)usos linguísticos, adquirindo estágios de relativa estabilidade em um dado grupo.

Paveau (2006) considera que as estruturas cognitivas metaforizadas funcionam como "prédiscursos" interiorizados, os quais seriam responsáveis pela nossa capacidade de atribuir e compreender sentidos. A metáfora funcionaria, então, como um organizador do (pré-)discurso nas suas mais diversas instâncias, considerando, para tanto, os aspectos cognitivos e discursivos integrados, quais sejam: organizador psíquico, a partir de esquemas partilhados; organizador cognitivo, a partir de conhecimentos e crenças; organizador discursivo, a partir de culturas de um determinado período em uma dada comunidade; organizador textual, responsável por mobilizar procedimentos de encadeamento transfrástico.

Recentemente, em Morais (2016), propusemos aproximar a "metáfora conceitual" de Lakoff e Johnson (1985) da "metáfora emergente" de Cameron e Deignam (2009) e dos "pré-discursos" de Paveau (2006) ao incorporar a releitura de Hall (2003) acerca da abordagem althusseriana da ideologia. Para Hall (2003, p. 184), a história contingencia a possibilidade de dados sentidos se sobreporem aos demais através do que ele denomina dupla articulação estrutura-prática, forma pela qual as estruturas atualizam-se, movimentam-se e concretizam-se: "Pode-se dizer que uma estrutura é o resultado de práticas anteriormente estruturadas. [...] A prática é a forma como uma estrutura é ativamente produzida".

A formação de cadeias enunciativas, ou associações conotativas, como intitula o sociólogo jamaicano, é responsável pela atribuição de sentido a um dado enunciado, visto que a sua emergência 
ocorre como prática discursiva em meio às possibilidades históricas envolvidas em uma dada situação enunciativa. Assim, as estruturas coexistiriam como em um sistema complexo, de modo que a emergência semi-estável de um sentido sobredeterminante (unidade na diferença) é historicamente contingenciada pelas práticas sociais (diferente no mesmo), não sendo nem fixa e nem anulável em si pela perda da posição na qual se encontrava. Partindo dos avanços trazidos pelos autores supracitados, em Morais (2016, p. 268), sistematizamos a categoria de "metáforas emergentes distribuídas", caracterizadas da seguinte maneira:

\section{Quadro 1 - Características das metáforas emergentes distribuídas}

\begin{tabular}{|c|c|}
\hline Sociais/históricas & $\begin{array}{l}\text { Emergem na/pela modulação entre sujeito e sociedade em uma dada } \\
\text { experiência/prática discursiva, a qual ocorre necessariamente pelos usos } \\
\text { de sistemas de restrição discursivos que funcionam como a priori } \\
\text { históricos. }\end{array}$ \\
\hline $\begin{array}{l}\text { Indeterminadas/ } \\
\text { Inatingíveis/ } \\
\text { Irredutiveis }\end{array}$ & $\begin{array}{l}\text { Não existem como coisas em si, essências que possam ser dominadas por } \\
\text { completo e hermeticamente organizadas como sistemas destacados da } \\
\text { história, mas como formas representáveis caracterizadas como sistemas } \\
\text { dinâmicos não-lineares produtos da relação entre estruturas e práticas } \\
\text { sociais. }\end{array}$ \\
\hline $\begin{array}{l}\text { Representáveis/ } \\
\text { Internalizáveis }\end{array}$ & $\begin{array}{l}\text { São relativamente apreensíveis, pois se pautam pela pobreza e } \\
\text { simplicidade de formas linguístico-discursivas que estão em relação com } \\
\text { outros signos em um dado imaginário grupal ou social. São determinadas } \\
\text { pelo exterior histórico e funcionam como memória cognitivo-discursiva } \\
\text { capaz de atualizar, consciente e/ou inconscientemente, "já-ditos" na } \\
\text { forma de "agora-ditos" emergentes em uma dada prática discursiva. }\end{array}$ \\
\hline Semi-estáveis & $\begin{array}{l}\text { Submetidas às inúmeras variações do sistema cultural do qual emergem, } \\
\text { funcionam como estados semi-estáveis autolimitados pela relação entre } \\
\text { paráfrase e polissemia e que, ao se alterarem, desencadeiam a } \\
\text { reorganização do conjunto da própria competência dos sujeitos. }\end{array}$ \\
\hline Contraditórias & $\begin{array}{l}\text { Irrompem como estruturas em dominância divididas em decorrência do } \\
\text { constante movimento interno de que lhes é constitutivo, surgindo como } \\
\text { singularidades contingentes organizadas como o "diferente no mesmo" e } \\
\text { como a "unidade na diferença". }\end{array}$ \\
\hline $\begin{array}{c}\text { Discursivamente } \\
\text { experenciáveis }\end{array}$ & $\begin{array}{l}\text { São sensíveis na medida em que funcionam como sistemas de restrição } \\
\text { dos discursos e emergem em uma dada experiência discursiva imaginada } \\
\text { como o real em si. A experiência não funciona como a priori ao discurso, } \\
\text { mas surge da dupla articulação entre estrutura e prática, na qual os } \\
\text { discursos são indeterminados, embora internalizáveis e representáveis, } \\
\text { passando a funcionar como competências cognitivo-discursivas na forma } \\
\text { de a priori históricos que possibilitam pensar/agir na/pela linguagem. }\end{array}$ \\
\hline Intersubjetivas & $\begin{array}{l}\text { Cada experiência discursiva possibilita a emergência de uma dada } \\
\text { posição-sujeito em relação ao coenunciador, a qual é modulada de acordo } \\
\text { com a interação entre os sistemas de restrição discursivos internalizados } \\
\text { (memória cognitivo-discursiva) e o acontecimento histórico em uma } \\
\text { dada condição de produção discursiva. }\end{array}$ \\
\hline
\end{tabular}




\begin{tabular}{|c|c|}
\hline $\begin{array}{l}\text { Reais, simbólicas } \\
\text { e imaginárias } \\
\quad(\text { RSI })\end{array}$ & $\begin{array}{l}\text { São reais na medida em que são materialidades simbólicas produzidas } \\
\text { na concretude das relações históricas contraditórias humanas, as quais } \\
\text { possibilitam a emergência de formações imaginárias. Dessa relação, } \\
\text { constitui-se sua natureza ideológica, na qual os sentidos emergem de } \\
\text { acordo com as relações práticas que estabelecem com os imaginários dos } \\
\text { grupos sociais. }\end{array}$ \\
\hline Distribuídas & $\begin{array}{l}\text { Externalizadas em distintos lugares de memória, com os quais estão em } \\
\text { constante inter-relação e interdependência na ecologia da comunicação } \\
\text { humana, tais como a memória dos/nos sujeitos, das/nas instituições e } \\
\text { dos/nos diferentes artefatos humanos. }\end{array}$ \\
\hline Tipológicas & $\begin{array}{l}\text { ESTRUTURAIS, pela relação constitutiva do atravessamento do outro, } \\
\text { isto é, ocorre quando um termo X adquire o sentido de um termo Y; } \\
\text { ONTOLÓGICAS, pela forma como atribuem aos signos um sentido } \\
\text { supostamente transcendente que os tornam substâncias discretas, } \\
\text { descritas e com características humanas. Neste caso, há uma tendência a } \\
\text { se apresentarem como metalinguagem e se vincularem aos discursos } \\
\text { constituintes, emergindo como produto e apagando-se como processo; } \\
D E O R I E N T A C \tilde{A} O \text {, pelo modo como atribuem axiologias socialmente } \\
\text { positivas ou negativas aos signos, a depender dos seus atrelamentos aos } \\
\text { sentidos dominantes/hegemônicos em uma dada sociedade ou grupo. }\end{array}$ \\
\hline
\end{tabular}

Para operacionalizar a análise, no presente texto, faremos uso dessa categoria, a qual se apresenta como aporte teórico-metodológico que aproxima a epistemologia da Análise do Discurso (PÊCHEUX, 2009; PAVEAU, 2006) daquela dos estudos cognitivos da metáfora (LAKOFF; JOHNSON, 1985; CAMERON; DEIGNAM, 2009). Ademais, ancorando-nos na abordagem que sugerimos em Morais (2016) para análises de discursos de ódio, organizaremos os enunciados analisados em cadeias enunciativas/associações conotativas (HALL, 2003), marcadas por relações de implicação semântica através do símbolo “ $\rightarrow$ ”, permitindo perceber a construção identitária do eu e do outro; em seguida, avaliaremos a constituição das metáforas emergentes distribuídas através da fórmula argumentativa "se X é Q, logo, Y é não-Q", onde X = não-Y.

Para finalizar, na seção seguinte, examinaremos quatro enunciados publicados nos anos de 2015 e 2016 pelo então deputado federal Jair Bolsonaro em seu perfil oficial no Facebook, os quais compõem um corpus em processo de montagem sobre o discurso político da extrema-direita brasileira na atualidade. Além de publicações nos perfis oficiais da família Bolsonaro no Facebook e Twitter, temos coletado entrevistas e matérias jornalísticas relatando diretamente seus posicionamentos ao longo das suas carreiras políticas. 


\section{Por Deus, Pela pátria e Pela Família: o "CidAdão de BeM" COMO ATOR POlítico no BRASIL}

O fenômeno da intolerância tem assolado muitas sociedades no mundo contemporâneo. Na Europa, por exemplo, os partidos de extrema-direita conseguiram, em 2017, ganhos eleitorais significativos, como indica a BBC (2018): Alemanha, Alternative for Germany (12,6\%); Áustria, Freedom Party (26\%); Dinamarca, Danish People's Party (21\%); Finlândia, The Finns (18\%); França, Front National (13\%), além do fato de que Marine Le Pen, a principal representante da extrema-direita francesa na atualidade, obteve $34,1 \%$ dos votos nas eleições presidenciais de 2017; Holanda, Freedom Party (13\%); Hungria, Jobbik (19\%); Itália, The League (17,4\%); República Checa, Freedom and Direct Democracy (11\%); Suécia, Sweden Democrats (17,6\%); Suíça, Swiss People's Party (29\%).

Nos Estados Unidos, Donald Trump se elegeu pelo Partido Republicano com aproximadamente 59.937.338 de votos, responsáveis pela sua vitória em 29 Estados, somando 290 votos no Colégio Eleitoral (BBC, 2016). No Brasil, o maior país da América Latina, o presidente Jair Messias Bolsonaro (PSL) ${ }^{6}$, foi eleito em 27 de outubro de 2018 com 57,8 milhões de votos ou 55,13\% dos votos válidos, equivalendo a 39,3\% do eleitorado total no país (ALVES, 2018). Durante a campanha eleitoral, defendeu, dentre outras coisas, a ditadura militar brasileira (1964-1985), a tortura e a perseguição às minorias, às esquerdas políticas e aos movimentos sociais, opondo-se, por conseguinte, aos direitos humanos.

Segundo pesquisa do Datafolha de 02 de outubro de 2018 (apud G1, 2018), o perfil do eleitorado de Jair Bolsonaro era composto por 55\% de homens e 45\% de mulheres; $15 \%$ na faixa etária de 16 a 24 anos, 24\% entre 25 e 34 anos, $20 \%$ entre 35 e 44 anos, 22\% entre 45 e 59 e $18 \%$ com 60 anos ou mais; 22\% possuíam o Ensino Fundamental, 47\%, o Ensino Médio e 32\%, o Ensino Superior; $28 \%$ ganhavam até 2 salários mínimos, $43 \%$, entre 2 e 5, 19\%, de 5 a 10, 8\%, 10 ou mais e $3 \%$ se recusaram a responder ou não sabiam; $48 \%$ moravam na região Sudeste, $20 \%$, na Sul, 16\%, na Nordeste, $8 \%$, na Centro-Oeste e 7\%, na Norte. Na pesquisa do Datafolha de 10 de outubro de 2018 (apud BRANDINO, 2018), o então presidenciável possuía a intenção de voto de 59\% dos brancos, 47\%, dos pardos e 37\%, dos pretos (neste grupo, seu adversário, Fernando Haddad (PT), possuía 45\% das intenções).

\footnotetext{
${ }^{6}$ O presidente Jair Bolsonaro foi filiado a vários partidos ao longo da sua carreira política, quais sejam: de 1988 a 1993 , Partido Democrata Cristão; de 1993 a 1995, Partido Progressista Reformador; de 1995 a 2003, Partido Progressista Brasileiro; de 2003 a 2005, Partido Trabalhista Brasileiro; em 2005, Partido da Frente Liberal; de 2005 a 2016, Partido Progressista; de 2016 a 2018, Partido Social Cristão; em 2018, filiou-se ao Partido Social Liberal, com o qual se elegeu presidente. Essa mobilidade partidária, de um lado, aponta para a fragilidade do projeto político encampado pelo presidente e, de outro, para o enfraquecimento do sistema partidário como estrutura representativa no momento atual do país, gerando uma tendência à personificação da política.
} 
Ao corrigir estatisticamente os dados da pesquisa Datafolha de 25 de outubro de 2018 a respeito do perfil religioso desse eleitorado, Alves (2018) chega às seguintes cifras: 29.795.232 de católicos, 21.595.284 de evangélicos (grupo no qual conseguiu a maior diferença de votos em relação ao seu concorrente, de 11.552.780 votos), 312.975 de religiões de matriz afro-brasileira, 1.721.363 de espíritas, 709.410 de outras religiões, 3.286.239 de sem religião e 375.570 de ateus e agnósticos, totalizando 57.796,074 de votos. Importante destacar que o candidato Fernando Haddad vence em três grupos nessa sondagem: o das religiões de matriz afro-brasileira, recebendo 755.887 votos, o dos sem religião, recebendo 4.157.381 de votos, e o de ateus e agnósticos, recebendo 691.097 votos.

Tais dados nos permitem avaliar as características do público eleitor de Bolsonaro auditório -, o terceiro a quem destina suas falas como locutor. Dentre as informações supracitadas, interessa-nos perceber a boa recepção do discurso político de extrema-direita no público masculino, branco, cristão católico ou evangélico, da região Sudeste, na faixa de 25 a 59 anos de idade, com Ensino Médio e Superior e com renda entre 2 e 5 salários mínimos.

Além disso, o apoiador de Jair Bolsonaro utiliza bastante as redes sociais, como pode ser demonstrado pelos 8 milhões de seguidores do seu perfil oficial no Facebook às vésperas da eleição, no dia 26 de outubro de 2018, sendo que começou a campanha em 31 de agosto de 2018 com aproximadamente 5,5 milhões (GORTÁZAR, 2018). Para fins de comparação, em 16 de fevereiro de 2019, esse número chega a 10.584.214 seguidores. Vejamos, então, uma de suas postagens, realizada em 18 de julho de 2015:

Quarta-feira, em sessão solene, saudei o Jornal O GLOBO pelos seus 90 anos. Recomendei, da Tribuna, a leitura do editorial - JULGAMENTO DA REVOLUÇÃO - de 07/outubro/1984, assinado por ROBERTO MARINHO: "Participamos da Revolução de 1964, IDENTIFICADOS COM OS ANSEIOS NACIONAIS de PRESERVAÇÃO DAS INSTITUIÇÕES DEMOCRÁTICAS, ameaçadas pela RADICALIZAÇÃO IDEOLÓGICA, GREVES, DESORDEM SOCIAL e CORRUPÇÃO GENERALIZADA...." O ambiente político de hoje (com milhares de agentes cubanos, ...) está pior que o pré 02/abril/1964, data em que o Congresso Nacional CASSOU o mandato de João Goulart. O PT se prepara para NÃO DEIXAR O PODER por quaisquer que sejam os meios DEMOCRÁTICOS ... O desarmamento da população de bem, a luta de classes, o desgaste dos valores da família, ... são apenas algumas das faces da esquerda brasileira na busca da perpetuação do poder (BOLSONARO, 2015a).

No enunciado, há a construção de dois grupos antagônicos: de um lado, a população de bem, do outro, a esquerda brasileira e o Partido dos Trabalhadores (PT). Em oposição lógica às pessoas/cidadãos de bem, haveria os não-cidadãos de bem; infere-se, então, que o cidadão de bem não só não é esquerdista/petista, como também possui por princípio sua negação política, de modo que ambos os grupos estão dispostos de maneira mutuamente excludentes. O posicionamento 
conflituoso entre tais grupos decorreria do fato de a esquerda brasileira ser anti-nacional, antidemocrática, ideologicamente radical, grevista, desordeira, corrupta e comunista. Logo, a favor do desarmamento da população de bem, da luta de classes e do desgaste dos valores da família. Em decorrência disso, citando o editorial do antigo proprietário do jornal O Globo, Roberto Marinho, o então parlamentar propõe uma ressignificação da ditadura militar brasileira (1964-1985) como Revolução, visto que, como reação à suposta ameaça dos "terroristas de esquerda", a subida dos militares ao poder teria sido uma medida necessária à garantia da ordem, das instituições democráticas e dos anseios nacionais.

Para o parlamentar, de forma semelhante ao que ocorrera em 1964, na atualidade, novamente, haveria o perigo de ruptura do status quo político, econômico e social, pois tanto as instituições como os cidadãos estariam sendo acuados pelo domínio das pautas ditas esquerdistas. Seguindo essa estratégia argumentativa, o outro - indesejado - passa a ser o culpado pela própria violência sofrida, pois entende-se que, paradoxalmente, as agressões e o regime militar ou estado de exceção seriam meios legítimos de manutenção da democracia e a violência seria a forma de garantir o respeito à alteridade, ao diálogo e à pluralidade.

Dito isso, podemos construir a seguinte cadeia enunciativa: (I) população de bem $\rightarrow$ cidadão de bem $\rightarrow$ nacionalista $\rightarrow$ democrática $\rightarrow$ capitalista $\rightarrow$ trabalhadora $\rightarrow$ ordeira $\rightarrow$ honesta $\rightarrow$ a favor do armamento da população $\rightarrow$ a favor da harmonia corporativa entre os grupos sociais $\rightarrow$ a favor da família $\rightarrow$ excluída do poder representativo. Por oposição, o “esquerdista” é definido como: (II) nãopopulação de bem $\rightarrow$ não-cidadão de bem $\rightarrow$ não-nacionalista $\rightarrow$ não-democrático $\rightarrow$ comunista $\rightarrow$ grevista $\rightarrow$ desordeiro $\rightarrow$ corrupto $\rightarrow$ a favor do desarmamento da população $\rightarrow$ a favor da luta de classes $\rightarrow$ a favor do desgaste dos valores da família $\rightarrow$ domina o poder representativo.

Tal organização argumentativa se pauta em uma orientação axiológica que positiva/legitima a primeira série associativa, o eu/nós constituído por seus pares institucionais, eleitores e apoiadores, e negativa/nega a segunda, os esquerdistas, isto é, o outro, seja ele representante político ou não. Aproximadamente quatro meses após, em 14 de novembro de 2015, o congressista publica a seguinte mensagem, também em seu perfil oficial no Facebook:

P/Face - Hoje A entrada de estrangeiros, sem qualquer controle, permite que infiltrados (escória) levem o terror para o seio dos acolhedores. Dilma Rousseff anunciou, na ONU, que o Brasil está de braços abertos para receber todos os refugiados do Norte da África. Estaríamos livres do terror? Já que o PT se nega em termos uma lei contra o terrorismo? Depois da França, alguns ainda continuarão a me acusar de "xenófobo" ou extremista de direita? (BOLSONARO, 2015b).

O sintagma "P/Face - hoje" revela a importância dessa rede social como ferramenta potencializadora do seu diálogo com o seu público. Constrói-se, desse modo, um contrato 
comunicacional ancorado no acordo tácito em torno de interesses comuns nesse grupo virtual, no qual o presidenciável divulga suas posições políticas, sem intermediários, e seus seguidores tanto acompanham suas ações quanto interagem a respeito de um dado tema político, como se houvesse um diálogo direto com o seu representante. Ademais, constrói-se um efeito de intimidade entre o político e os seus - potenciais - eleitores, constituindo uma zona de identificação dinâmica entre as partes, seja no sentido institucional, na medida em que o então deputado federal representava uma casa legislativa e seus deveres formais, seja no sentido pessoal, na medida em que o acompanhamento da sua rotina individual e familiar permite ultrapassar o aspecto meramente ritualístico para garantir uma espécie de relação amistosa. Fortalecem-se, assim, os vínculos emocionais e a capacidade persuasiva do orador em relação ao seu auditório, garantindo uma projeção imaginária mais empírica - "real" - a ambos.

No que concerne às cadeias conotativas entre os distintos signos, a oposição semântica parece se atualizar em relação ao enunciado anterior a partir do posicionamento dos acolhedores (= cidadãos de bem), de um lado, e de Dilma Rousseff, do PT e dos infiltrados (= não-cidadãos de bem), do outro. Na esteira dessa diferenciação estanque/radical - essencializada - entre os dois grupos, o parlamentar suscita o medo da população brasileira frente à abertura das fronteiras aos refugiados, retomando o problema da segurança nacional pela presumida necessidade de aprovar uma legislação antiterrorista no país capaz de criar mecanismos jurídicos específicos contra aqueles que atentem contra o Estado brasileiro. A associação parcial entre estrangeiros, infiltrados e escória e entre Dilma Rousseff, PT e a suposta oposição destes à Lei Antiterrorismo justificaria tanto as acusações de que alguns dos refugiados podem ser terroristas quanto as de irresponsabilidade da Presidente, que seria incapaz de decidir sobre o tema e seria permissiva7 com a "escória", sendo ambos os grupos negados pelo ódio.

Como estratégia argumentativa, conforma-se um eu/nós que busca se desvencilhar das acusações de extrema-direita e de xenófobo, almejando legitimar suas propostas no espectro político nacional na atualidade. $\mathrm{O}$ autor reconhece, então, que seu papel institucional deve prezar pela nãoincitação à intolerância, isto é, que essa negação do outro deve se pautar em determinadas regras do jogo político, o qual se ancora em um "ideal social” democrático e republicano. Busca-se, assim, evitar a acusação de fomentar o desrespeito aos valores universais e à pluralidade, o qual romperia com o contrato tácito das refutações erísticas. Nesse intuito, observa-se a seguinte associação

\footnotetext{
${ }^{7}$ Importante lembrar que Dilma Rousseff combateu o regime militar brasileiro (1964-1985) através do Comando de Libertação Nacional - COLINA - e da Vanguarda Armada Revolucionária Palmares - VAR-PALMARES, chegando a ser presa e torturada em Juiz de Fora, São Paulo e Rio de Janeiro (KIEFER, 2012). Em vista disso, é considerada como ex-terrorista pelos apoiadores da ditadura militar no país.
} 
conotativa: (III) cidadãos de bem $\rightarrow$ acolhedores $\rightarrow$ ameaçados pelo terror/terrorismo; por oposição a: (IV) não-cidadãos de bem $\rightarrow$ entrada de estrangeiros/refugiados $\rightarrow$ entrada de infiltrados/escória $\rightarrow$ permissividade/incompetência da presidente Dilma Rousseff e do PT.

Em 17 de abril de 2016, na sessão de julgamento da admissibilidade do processo de impeachment da presidente Dilma Rousseff (PT), na Câmara dos Deputados, o deputado profere o seguinte voto:

Nesse dia de glória para o povo brasileiro, tem um nome que entrará para a história nessa data, pela forma como conduziu os trabalhos nessa casa, parabéns presidente Eduardo Cunha. Perderam em 64, perderam agora em 2016. Pela família e pela inocência das crianças em sala de aula que o PT nunca teve, contra o comunismo, pela nossa liberdade, contra o Foro de São Paulo, pela memória do Coronel Carlos Alberto Brilhante Ustra, o pavor de Dilma Rousseff, pelo Exército de Caxias, por nossas Forças Armadas, por um Brasil acima de tudo e por Deus acima de todos, o meu voto é sim (BOLSONARO, 2016a. Transcrição).

Esse enunciado sintetiza um conjunto de posicionamentos ideológicos relevantes para a constituição do discurso ultraconservador do político, tais como: o discurso econômico (neo)liberal ${ }^{8}$, manifesto pelo signo "liberdade" e pelos sintagmas "contra o comunismo", "contra o Foro de São Paulo" - organização considerada comunista; o discurso conservador cristão, manifesto por sintagmas como "pela família", "pela inocência das crianças em sala de aula" - alusão à proposta do "Kit Escola sem Homofobia" do Ministério da Educação - e "Deus acima de todos"; e pelo discurso nacionalista militar/securitário-autoritário", manifesto por sintagmas como "pela memória do Coronel Carlos Alberto Brilhante Ustra" - reconhecido juridicamente como o principal torturador do período

\footnotetext{
${ }^{8}$ A respeito da relação entre as direitas e o discurso neoliberal no Brasil, Kaysel $(2015$, p. 68) ressalta: "[s]e antes da transição democrática, o apoio à ditadura era a principal baliza que definiria o pertencimento à direita, durante $\mathrm{o}$ processo de democratização, em especial no bojo do movimento constituinte (1987-1988), a direita abraçaria a defesa de políticas de liberalização econômica, ditas "neoliberais", como seu principal traço programático. Essa nova orientação [...] se aprofunda na década seguinte, com a formação de diferentes think tanks neoliberais com apoio de seus congêneres estadunidenses, sendo o pioneiro o Instituto Liberal do Rio de Janeiro (1983)". Como foge à proposta deste texto discutir as continuidades e descontinuidades entre os discursos liberal e neoliberal na extremadireita brasileira, destacamos apenas que é possível notar uma movimentação de posicionamento do então presidenciável Jair Bolsonaro de liberal para neoliberal, decorrente, principalmente, da sua tentativa de alinhamento aos grupos empresariais e financeiros associados à sua campanha. Isso permite mostrar a historicidade do discurso analisado, que deve ser entendido como "contraditório internamente" (diferente no mesmo), embora assuma uma coerência global (unidade na diferença), e como submetido às contingências do processo histórico. Compreendendo que há contradições e sobredeterminações no discurso da extrema-direita brasileira, conforme discutimos na nota de número 4 do presente texto, colocamos o prefixo "neo" entre parênteses. Para uma discussão aprofundada sobre a descontinuidade entre o discurso liberal clássico e o neoliberal, remetemos novamente a Dardot e Laval (2016). Cumpre-nos destacar, ainda: se o neoliberalismo parece ser um componente fundamental no discurso da extremadireita brasileira, para Rancière (2014), a constante destruição do espaço da política na Europa pelo modelo neoliberal após a década de 1960 e a crescente falência representativa e jurídica do Estado em prol do poder financeiro e corporativo seriam duas das principais causas do crescimento de grupos de extrema-direita nacionalistas e antiliberais nesse continente.

${ }^{9}$ Ver nota 2.
} 
militar brasileiro, inclusive da presidente Dilma Rousseff -, "pelo Exército de Caxias" - Duque de Caxias é o patrono do Exército Brasileiro -, "por nossas Forças Armadas" e "Brasil acima de tudo".

Na passagem "Perderam em 64, perderam agora em 2016", mais uma vez, há uma espécie de atualização da memória histórica brasileira, pois remete-se ao golpe militar de 1964 para definir quem é o "eu/nós vencedor" e o "outro/inimigo perdedor" na situação enunciativa em questão. Tanto naquele acontecimento histórico como na atualidade, o que estaria em jogo seria a manutenção da ordem na sociedade brasileira pelos cidadãos de bem frente aos comunistas, os quais eram/são tidos como uma espécie de infiltrados/escória no Brasil que buscavam/buscam destruir os valores fundamentais do Estado brasileiro, tais como o Deus cristão, a família tradicional, a ideia de nação e a propriedade privada. Temos, com isso, a seguinte cadeia enunciativa: (V) cidadão de bem $\rightarrow$ a favor da Revolução de $1964 \rightarrow$ a favor da família $\rightarrow$ a favor da liberdade $\rightarrow$ a favor da inocência das crianças $\rightarrow$ a favor do exército de Caxias/das nossas forças armadas $\rightarrow$ a favor de um Brasil acima de tudo $\rightarrow$ a favor de Deus acima de todos. Como oposição diametral aos valores do "cidadão de bem”, conforma-se: (VI) não-cidadão de bem $\rightarrow$ a favor do PT $\rightarrow$ a favor do Foro de São Paulo $\rightarrow$ a favor do comunismo.

Nesse pronunciamento, há a tentativa de estabelecer uma interação discordante em relação aos seus opositores políticos, visto que busca-se manter o script do rito parlamentar em execução, embora não cogitando qualquer consenso, acordo ou negociação. Seu público eleitor, principal destinatário da enunciação, materializa-se na forma de um terceiro - tiers - ausente da sessão de votação na Câmara. Contudo, ao aludir positivamente à ditadura militar e a um dos principais torturadores desse período histórico, o discurso do congressista rompe com o pacto democrático, passando a se caracterizar como um discurso intolerante.

Isso demonstra a instabilidade da confluência entre a refutação erística - quando a negação da alteridade mantém um dado contrato comunicacional - e o discurso intolerante -quando ocorre a apresentação de sanções morais e físicas ao grupo considerado inimigo - na organização argumentativa do discurso da extrema-direita brasileira. Ao se definir como proposta política, tal discurso procura legitimar seu dizer, almejando se justificar pelo direito à liberdade de expressão, bem como se desvencilhar da acusação de discurso de ódio. Para tanto, comumente, o extremista se considera como o verdadeiro "excluído", "ameaçado", "perseguido" e "acuado", alterando, estrategicamente, a posição de "autoritário/opressor/agressor" para a de "democrático/oprimido/vítima", situação que criaria empatia com o seu público pelas emoções do medo e do ódio e autorizaria medidas de exceção.

Tanto nos ambientes virtuais como nos institucionais, esses dizeres podem gerar reações que oscilam entre o apoio radical ao direito à liberdade de dizer o que pensa - como suposta "expressão 
da verdade" - e a repulsa daqueles que priorizam o respeito ao diálogo, à alteridade e à diversidade. A ruptura do script da refutação erística em prol do discurso intolerante nesse pronunciamento fica patente pelo fato de que grupos estudantis de esquerda e a favor dos direitos humanos ocuparam a frente da casa do parlamentar uma semana após esse ocorrido, em 24 de abril de 2016. Acerca do episódio, Jair Bolsonaro publica:

Globonews pediu-me uma nota sobre o episódio de hoje: 'Estava em minha residência nessa manhã quando uns 100 desocupados, com bandeiras vermelhas, fecharam a entrada do meu condomínio. Diante de tantas ameaças mandei-lhes o seguinte recado: 1 - Se invadirem, não sairão; 2 - Minha propriedade privada é sagrada; 3 - Minha esposa e filhas de 13 e 5 anos nunca serão reféns de vocês; 4 Por isso o PT desarmou o povo brasileiro.' Jair Bolsonaro Capitão - RJ - Artilharia Deputado Federal - PSC - RJ (BOLSONARO, 2016b).

Algumas questões se mostram relevantes para a nossa interpretação neste texto, quais sejam: primeira, a publicação de uma declaração em seu próprio perfil na rede social garantiria uma relação mais direta com seu público; segunda, a definição dos manifestantes como "desocupados" e "com bandeiras vermelhas" enquadrá-los-ia no grupo dos que não valorizariam o trabalho como forma de inserção na sociedade, parafraseando, através de saberes do senso comum, a oposição entre o discurso econômico (neo)liberal e o discurso comunista; terceira, o uso de termos militares para descrever sua imagem e o acontecimento - "ameaçam invadir" e "fazer reféns" - e sua assinatura como "Capitão de Artilharia" construiria um cenário análogo a uma batalha ou a uma situação extraordinária de desordem, almejando legitimar o uso da força - simbólica e física - como forma de revide, visto que tratar-se-iam de "defensores" contra "inimigos"; quarta, a definição de propriedade privada como direito sagrado e fundamento da ordem pública aponta para uma interface possível entre o discurso (neo)liberal e o discurso religioso; quinta, a apresentação da condição particular da sua "família" como grupo ameaçado, em relação metonímica ${ }^{10} \mathrm{com}$ a "família brasileira", endossaria a necessidade de autorização pública para o porte legal de armas aos demais cidadãos, aproximando o discurso conservador cristão do discurso nacionalista militar/securitário-autoritário; sexta, a oposição entre PT - em direta associação com os "desocupados", "bandeiras vermelhas" e "invasores" - e povo

\footnotetext{
${ }^{10}$ A respeito da categoria de metonímia, Lakoff e Jonhson (1985, pp. 46-7) tratam, especialmente, da sinédoque, definida como o processo pelo qual os seres humanos conseguem tomar a parte pelo todo, tais como: o produtor pelo produto; o objeto utilizado pelo usuário; o responsável pelo executante; a instituição pelas pessoas responsáveis; o lugar pela instituição; e, por fim, o lugar pelo evento (LAKOFF; JOHNSON, 1985, pp. 46-7. Tradução livre). De forma semelhante, para Pêcheux (2009, p. 153), esse fenômeno demonstra o funcionamento discursivo "da relação da parte com o todo, da causa com o efeito, do sintoma com o que ele designa, etc". Para o analista do discurso, tal fenômeno decorreria do funcionamento do "discurso-transverso" (organização interdiscursiva) em relação à articulação intradiscursiva do texto, sendo o primeiro o meio pelo qual os discursos remetem ao seu exterior para se articular na forma do segundo, isto é, pela linearização. A respeito das tentativas de aproximar o Realismo Experiencial do viés pecheutiano da Análise do Discurso, consultar Paveau (2006) e Morais (2015).
} 
brasileiro - em menção implícita à "população de bem" - novamente estabeleceria uma relação metonímica entre a situação vivenciada pelo então deputado e aquela vivenciada pelo país - a descrição da experiência particular permitiria criar empatia pública e despertar sensações semelhantes por analogia; por fim, sétima, o autor assina como "Deputado Federal - PSC - RJ", legitimando seu enunciado no âmbito do discurso político institucional.

Tratar-se-ia, além de um ex-militar, de um representante do Congresso Nacional, que, como qualquer cidadão brasileiro, possuiria o direito de defender a si, sua família e sua propriedade, podendo, se necessário, “eliminar” aqueles que lhe ameaçam. Constitui-se, assim, a seguinte cadeia: (VII) cidadão de bem $\rightarrow$ ameaçado $\rightarrow$ defensor da propriedade privada $\rightarrow$ defensor da família $\rightarrow$ defensor do direito ao porte de armas $\rightarrow$ defensor do povo brasileiro; contra: (VIII) não-cidadão de bem $\rightarrow$ desocupado $\rightarrow$ com bandeiras vermelhas $\rightarrow$ invasores $\rightarrow$ PT. Se somarmos as associações conotativas trabalhadas até então, temos as seguintes relações semânticas para o discurso político da extrema-direita brasileira na atualidade:

$1^{\text {a) }}$ População de bem $\rightarrow$ cidadão de bem $\rightarrow$ (extrema) direita política $\rightarrow$ nacionalista/patriota/usa as cores da bandeira brasileira $\rightarrow$ democrática $\rightarrow$ capitalista $\rightarrow$ (neo)liberal $\rightarrow$ trabalhadora/ordeira/moralista/honesta/competente $\rightarrow$ excluída/ameaçada do/pelo poder representativo $\rightarrow$ ameaçada pelo terror/pela invasão interna e externa $\rightarrow$ a favor do direito ao porte de armas $\rightarrow$ a favor da harmonia paternalista corporativa/hierárquica entre os grupos sociais $\rightarrow$ a favor da família cristã $\rightarrow$ a favor dos militares $\rightarrow$ a favor da liberdade de mercado/da propriedade privada/do indivíduo $\rightarrow$ defensora do povo brasileiro/da pátria brasileira;

\section{Por oposição a:}

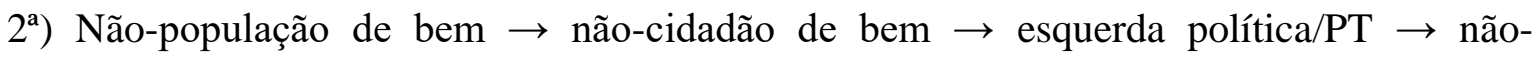
nacionalista/não-patriota/usa bandeiras vermelhas $\rightarrow$ anti-democrática $\rightarrow$ comunista $\rightarrow$ desocupada/grevista/desordeira/imoral/corrupta/incompetente $\rightarrow$ domina/busca se perpetuar o/no poder representativo $\rightarrow$ terrorista/infiltrada/invasora/escória $\rightarrow$ a favor do desarmamento da população $\rightarrow$ a favor da luta de classes na sociedade $\rightarrow$ a favor da destruição dos valores da família cristã $\rightarrow$ contra os militares/o regime militar brasileiro $\rightarrow$ contra a liberdade de mercado/a propriedade privada/o indivíduo $\rightarrow$ ameaça ao povo brasileiro/à pátria brasileira.

Seguindo a fórmula argumentativa "se X é Q, logo, Y é não-Q" (MORAIS, 2016), temos que, se o cidadão de bem é heterossexual, (neo)liberal, militarista, patriótico e cristão, logo, o nãocidadão de bem é não-heterossexual, não-neoliberal, não-militarista, não-patriótico, não-cristão, em que o conceito de cidadão de bem - metáfora ontológica - adquire positividade - metáfora de 
orientação - pela sua associação simbólica aos grupos dominantes na sociedade brasileira, organizada pela metáfora o outro é inimigo - metáfora estrutural -.

A certeza de estar do lado do "bem", como noção transcendental da moral, do bom, do correto e do dever ser, implica, automaticamente, a negação da alteridade, posta passionalmente do "lado do mal". No discurso político da extrema-direita, a intolerância política ao outro (não-ser) funciona como uma espécie de organizadora da discordância de base em relação às demais (étnicoracial, linguística, estética, religiosa, socioeconômica etc). Ademais, como vimos, tal discurso emerge na tensão entre a interação discordante - refutação erística - e o discurso intolerante por meio da interface entre o discurso político, fundamento da legitimidade institucional dos dizeres, o discurso conservador cristão, fundamento dos valores de pureza e de tradição, o discurso nacionalista militar, fundamento das acepções de ordem, hierarquia e autoridade, e o discurso econômico (neo)liberal, fundamento das noções de indivíduo, liberdade e propriedade privada.

\section{CONSIDERAÇÕES FINAIS}

O presente texto é uma modesta tentativa de contribuir para a compreensão da atual organização sócio-política brasileira, em especial no que tange às características discursivas dos grupos extremistas da direita política nacional. Para tanto, alicerçamo-nos nas contribuições de Barros (2007), no que concerne às características dos discursos e identidades intolerantes, nas de Emediato (2011), no que se refere à definição das interações discordantes, e nas de Morais (2016), no que toca às potencialidades dos usos teórico-metodológicos das metáforas emergentes distribuídas e de fórmulas argumentativas para a análise dos discursos de ódio.

Em síntese, a partir de uma abordagem discursivo-cognitiva da linguagem humana, considerando, portanto, os aspectos sócio-históricos que incidem na organização imaginária das estruturas simbólicas humanas, pudemos perceber como a memória discursiva da ditadura militar brasileira tem sido ressignificada positivamente no contexto político atual no intuito de definir os cidadãos de bem (metáfora ontológica) como atores políticos superiores (metáfora de orientação) aos seus inimigos (metáfora estrutural): a esquerda política, os excluídos, os movimentos sociais ou qualquer grupo que almeje transformar o status quo - herdado historicamente - das relações econômicas e de poder na sociedade brasileira contemporânea. Como estratégia argumentativa, tais grupos se posicionam como os verdadeiros “oprimidos" e "perseguidos", fundamentando-se em uma cadeia semântica que aproxima - interdiscursivamente - os discursos político, cristão conservador, nacionalista militar e neoliberal. 


\section{REFERÊNCIAS}

BARROS, D. L. P. de. 2007. A identidade intolerante no discurso separatista. Filologia Linguística Portuguesa, v. 9, p. 147-67, 2007.

CAMERON, L.; DEIGNAM, A. A emergência da metáfora no discurso. Cadernos de Tradução, 25, p. 143-67, 2009.

CHARAUDEAU, P. Discurso político. São Paulo: Editora Contexto, 2008.

DARDOT, P.; LAVAL, C. A nova razão do mundo: ensaio sobre a sociedade neoliberal. São Paulo: Boitempo, 2016.

EMEDIATO, W. Diálogos regulares e interações discordantes. Gláuks, n. 11, v. 1, p. 145-74, 2011. Disponível em: www.revistaglauks.ufv.br/artigo/100. Acesso em: 27 abr. 2016.

FAGANELLO, M. A. Bancada da Bala: uma onda na maré conservadora. In: CRUZ, S. V; Kaysel, A; CODAS, G. (org.). Direita, volver!: o retorno da Direita e o ciclo político brasileiro, São Paulo: Edição Fundação Perseu Abramo, 2015. p. 145-61.

HALL, S. Da diáspora: Identidades e mediações culturais. Brasil: Editora UFMG, 2003.

KAYSEL, A. Regressando ao Regresso: elementos para uma genealogia das direitas brasileiras. CRUZ, S. V; Kaysel, A; CODAS, G. (org.). Direita, volver!: o retorno da Direita e o ciclo político brasileiro. São Paulo: Edição Fundação Perseu Abramo, 2015. p. 49-74.

LAKOFF, G.; JOHNSON, M. Les métaphores dans la vie quotidienne. França: Les Éditions de Minuit, 1985.

LÖWY, M. Conservadorismo e extrema-direita na Europa e no Brasil. Serviço Social \& Sociedade, $\mathrm{n}^{\circ} 124,2015$. p. 652-64.

MORAIS, A. R. A. A metáfora como elo entre a Análise do Discurso, o Realismo Experencial e os Sistemas Complexos. In: CONGRESSO INTERNACIONAL SOBRE METÁFORA NA LINGUAGEM E NO PENSAMENTO, 5., 2015, Belo Horizonte. Anais [...] Belo Horizonte: Fale/UFMG, 2015. p. 254-269.

MORAIS, A.R.A. O preconceito contra os nordestinos nas redes sociais. In: LARA, G. M. P.; LIMBERTI, R. de C. P. (org.). Representações do outro: discurso (des)igualdade e exclusão. $1^{\text {a }}$ ed. Belo Horizonte, MG: Autêntica, 2016. p. 260-75.

PAVEAU, M-A. Les pré-discours: sens, mémoire, cognition. França: Presses Sorbonne Nouvelle, 2006.

PÊCHEUX, M. Semântica e discurso: uma crítica à afirmação do óbvio. Campinas: Editora da Unicamp, 2009.

RANCIÈRE, J. 2014. O ódio à democracia. São Paulo: Boitempo Editorial. 
SILVEIRA, S. A. da. Direita nas redes sociais. CRUZ, S. V; Kaysel, A; CODAS, G. (org.). Direita, volver!: o retorno da Direita e o ciclo político brasileiro. São Paulo: Edição Fundação Perseu Abramo, 2015. p. 213-30.

VILLAZÓN, J. C. Velhas e novas direitas religiosas na América Latina: os evangélicos como fator político. CRUZ, S. V; Kaysel, A; CODAS, G. (org.). Direita, volver!: o retorno da Direita e o ciclo político brasileiro. São Paulo: Edição Fundação Perseu Abramo2015. , p. 163-75.

\section{Corpus e Matérias Jornalísticas}

ALVES, J. E. D. O voto evangélico garantiu a eleição de Jair Bolsonaro. Revista IHU on-line, 01 de novembro de 2018. Disponível em: http://www.ihu.unisinos.br/78-noticias/584304-o-votoevangelico-garantiu-a-eleicao-de-jair-bolsonaro. Acesso em: 14 fev. 2019.

ARANTES, P. E. Nova direita surgiu após junho, diz filósofo: depoimento. Revista Folha de São Paulo. Entrevista concedida a Eleanora de Lucena. 2014. Disponível em:

<www1.folha.uol.com.br/poder/2014/10/1541085-nova-direita-surgiu-apos-junho-dizfilosofo.shtml>. Acesso em: 25 abr. 2016.

BBC. Europe and nationalism: A country-by-country guide, 10 de setembro de 2018. Disponível em: https://www.bbc.com/news/world-europe-36130006. Acesso em: 14 fev. 2019.

BBC. Por que Hillary perdeu a eleição mesmo recebendo mais votos que Trump? 11 de novembro de 2016. Disponível em: https://www.bbc.com/portuguese/internacional-37948302. Acesso em: 14 fev. 2019.

BOLSONARO, J. O PT roubará a nossa liberdade? Facebook. 2015a. Disponível em: <www.facebook.com/jairmessias.bolsonaro/photos/a.213527478796246.1073741826.21185748229 6579/513541185461539/?type=3\&theater $>$. Acesso em: 26 abr. 2016.

BOLSONARO, J. Carta. Facebook. 2015b. Disponível em: <www.facebook.com/jairmessias.bolsonaro/photos/a.213527478796246.1073741826.21185748229 6579/556136917868632/?type=3\&theater $>$. Acesso em: 26 abr. 2016.

BOLSONARO, J. Nota. Facebook. 2016a. Disponível em:

<www.facebook.com/jairmessias.bolsonaro/photos/a.213527478796246.1073741826.21185748229 6579/621891257959864/?type=3\&theater $>$. Acesso em: 26 abr. 2016.

BOLSONARO, J. Voto do Deputado Jair Bolsonaro a favor do Impeachment. Youtube. 2016b. Disponível em: <www.youtube.com/watch?v=iUbI4cJv-NI>. Acesso em: 26 abr. 2016.

BRANDINO, G. Bolsonaro lidera entre eleitores brancos e pardos, e Haddad, entre pretos, diz Datafolha. Folha de São Paulo, 11 de outubro de 2018. Disponível em: https://www1.folha.uol.com.br/poder/2018/10/bolsonaro-lidera-entre-eleitores-brancos-e-haddadentre-pardos-e-pretos-diz-datafolha.shtml. Acesso em: 14 fev. 2019.

CHAUÍ, M. 2016. Sociedade brasileira: violência e autoritarismo por todos os lados: depoimento. Entrevista concedida a Juvenal Savian Filho e Laís Modelli. Revista Cult. 2016. Disponível em: <www.revistacult.uol.com.br/home/2016/02/sociedade-brasileira-violencia-e-autoritarismo-portodos-os-lados>. Acesso em: 25 abr. 2016. 
GORTÁZAR, N. G. Bolsonaro, um candidato que cresceu no Facebook e não quer sair de lá. $E l$ País, 26 de outubro de 2018. Disponível em:

https://brasil.elpais.com/brasil/2018/10/24/politica/1540388654_185690.html. Acesso em: 14 fev. 2019.

G1. Pesquisa Datafolha: veja perfil dos eleitores de cada candidato a presidente por sexo, idade, escolaridade, renda e região. 03 de outubro de 2018. Disponível em:

https://g1.globo.com/politica/eleicoes/2018/eleicao-em-numeros/noticia/2018/10/03/pesquisadatafolha-veja-perfil-dos-eleitores-de-cada-candidato-a-presidente-por-sexo-idade-escolaridaderenda-e-regiao.ghtml. Acesso em: 14 fev. 2019.

KIEFER, S. Documentos revelam detalhes da tortura sofrida por Dilma em Minas na ditadura. Estado de Minas. 17 de junho de 2012. Disponível em: <https://www.em.com.br/app/noticia/politica/2012/06/17/interna_politica,300586/documentosrevelam-detalhes-da-tortura-sofrida-por-dilma-em-minas-na-ditadura.shtml>. Acesso em: 23 ago. 2018.

RIBEIRO, R. J. Extrema-direita avança com ódio aos direitos humanos, diz filósofo: depoimento. Entrevista concedida a Roldão Arruda. Estadão. 2015. Disponível em:

$<$ http://politica.estadao.com.br/blogs/roldao-arruda/extrema-direita-avanca-com-odio-aos-direitoshumanos-diz-filosofo/>. Acesso em: 25 abr. 2016. 